\title{
Sticks and stones: How words and language impact upon social inclusion
}

\section{Kathy McKay}

School of Health

University of New England, Armidale

\section{Stuart Wark}

School of Rural Medicine

University of New England, Armidale

\section{Virginia Mapedzahama}

CRN for Mental Health and Well-Being in Rural and Regional Communities

University of New England, Armidale

School of Social Sciences and Psychology

University of Western Sydney

\section{Tinashe Dune}

CRN for Mental Health and Well-Being in Rural and Regional Communities

University of New England, Armidale

School of Science and Health

University of Western Sydney

\section{Saifur Rahman}

School of Rural Medicine

University of New England, Armidale 


\title{
Catherine MacPhail
}

School of Health

University of New England, Armidale

\begin{abstract}
Language framed as derogatory names and symbols can have implications for people and their life experiences. Within a Saussurian-inspired frame, and looking at ideas of stigma and social inclusion, this paper examines the use of language as a weapon within a social context of (changing) intent and meaning. Three examples of language use in mainstream society are analysed: 'retarded' which evolved from scientific diagnosis to insult; 'gay' as a derogatory adjective within popular culture; and, the way language around suicide is used to both trivialise and stigmatise those who are suicidal, as well as those who are bereaved.

Key words: Social inclusion, derogatory, stigma, retarded, gay, suicide
\end{abstract}

\section{Introduction}

Lisa: A Rose by any other name would smell as sweet.

Bart: Not if you called 'em Stenchblossoms.

Homer: Or Crapweeds.

Marge: I'd sure hate to get a dozen Crapweeds for Valentine's Day. I'd rather have candy.

Homer: Not if they were called Scumdrops.

'The Principal and the Pauper', The Simpsons, 1997, Season 9, Episode 180

The ability to use language, and to assign names to things, has traditionally been considered a 'gift' in Western linguistic and philosophical traditions (Harris, 1990). However, de Saussure (1910-1911) argued that words do more than name, they assign meaning and symbolism to the named things (Culler, 1976; Harris, 1987; Hurford, 1989). Words are not empty vessels linked together to create conversation; 
rather they carry vital information between speaker(s) and listener(s) outside of the basic information conveyed. Indeed, choice of words conveys meaning far beyond that of the words themselves; choice of language tells the listener about the speaker's lived experience and how they see the world (Devitt \& Sterelny, 1999; Garrett \& Baquedano-Lopez, 2002). Words do not have singular or static meanings and, consequently, it becomes vital to recognise the speaker's intent when words are used that may have both positive and negative meanings; there are literal definitions to dissect, as well as any underlying secondary messages (Garrett \& BaquedanoLopez, 2002). Critical discourse analysis is a process of examining how inherent, but often unrecognised, power relationships are associated with language usage and the choice of specific words. It attempts to uncover the hidden, implied and unconscious social constructs that are both developed and reinforced through the choice of words and language, and through this, seeks to recognise and highlight social inequities that language use can both promote and maintain (Forchtner, 2012; Gee, 2014).

Confusion and offense can arise when technically correct words that describe certain conditions or situations are subsequently misappropriated into general dayto-day usage with modified meanings. Keely and Fink (2011) commented that subsequent generations will often view potentially offensive words more liberally than the previous one. Examples of these changing denotations include words such as 'retarded' or 'gay', and phrases referring to actions including suicide such as 'I just wanted to kill myself'. Such words and phrases are used in daily communication often with no thought about their relevance to the literal meaning, or the potential emotional impact that their usage may have upon other individuals. The meanings signified with these words become lost in dismissive usage, leaving listeners hurt by seemingly callous language, or else the meanings act as weapons in language usage intended to hurt.

With respect to critical discourse analysis, it is important to differentiate between the concept of 'hate speak', which is a deliberate act of discrimination designed to denigrate an individual or group (e.g. Butler, 1997; Delgado \& Stefancic, 2004; Leets, 2002), and a more subtle and yet still harmful indirect action. Worldwide, there is considerable discussion around the need to monitor and even legislate against hate speak and hate crimes (Bleich, 2011), however, the casual use of formerly derogatory terms can get overlooked. This article examines the way in which language is used to change a person's experience into something generally 
and definitely negative and the implications when tragedy is trivialised without thought for the consequences. As both language, and those who use it, are social creatures and products, the words and phrases examined in this article have been placed within a social context and the analysis framed around (changing) intent and meaning. Here, three examples will be analysed. The first is the evolution of the word 'retarded' from scientific diagnosis to casual insult. The second is the use of the word 'gay' as a derogatory adjective within mainstream popular culture. The third is the way in which language around suicide is used which both trivialises and stigmatises those who are suicidal, as well as those who are bereaved.

\section{Retarded}

When Australia was colonised by the English in 1788, the first Governor Phillip was bestowed with the power to deal with, as he saw fit, people classified as 'idiots' (Shea, 1999). Over time, the words used to define and describe people with an intellectual impairment have changed around the world. Generally, the term 'intellectual disability' is used to describe an individual whose intellectual capacity is significantly lower than that of their typical counterparts (World Health Organisation, 2012). Other terms for intellectual disability include mental retardation, mental handicap, mental impairment, learning disability and developmental disability. Previously commonplace terms such as 'idiot', 'subnormal', 'handicapped', 'moron', 'imbecile' and 'feeble minded' are now largely and globally technically obsolete due to the negative connotations and implications associated with them (Lewis \& Kellett, 2004). For instance, in Australia intellectual disability has long replaced mental retardation within both research and wider public usage because of the negativity associated with the term 'retarded'.

Until May 2013, the term 'mental retardation' was still used in the United States of America (USA) in certain circles as it remained the definition in the current version of the Diagnostic and Statistical Manual of Mental Disorders IV-TR (APA, 2000). DSM-V, which was released in May 2013, has officially changed the diagnostic term 'mental retardation' to 'intellectual disability,' thereby bringing the DSM into alignment with contemporary terminology used within other health disciplines (APA, 2013). As an example of this movement away from using the term retarded, in 2009 the American Journal on Mental Retardation officially changed its 
name to the American Journal on Intellectual and Developmental Disabilities. The editor noted that:

in part, the change has been motivated by a desire to avoid the negative connotations that have come to be associated with the term mental retardation. I fully endorse this change in terminology because it reflects our field's commitment not only to our science but to the people whose lives we hope to improve through our efforts. Quite simply, the change in terminology is a tangible sign of our respect for, and solidarity with, people who have disabilities and their families (Abbeduto, 2009, p. 1).

Similarly, in 2010 US President Obama signed off on the Bill S. 2781 which officially removed the terms 'mental retardation' and 'mentally retarded' from all government policies, replacing them instead with the term 'intellectual disability' (US Congress, 2012). However, while this change is taking place in academic and political circles, words such as 'retarded' are being increasingly used in mainstream media and social networking platforms to describe the actions of people without any intellectual impairment (R-Word, 2012a).

For example, the movie Tropic Thunder had numerous characters refer to activities or actions as 'moronical' or 'retarded'. It spawned the phrase 'going the full retard' which has entered the vernacular to describe an action that is completely ridiculous and totally lacking in value (e.g. Urban Dictionary, 2009). This tacit promotion of the word retard within a popular movie has seen it quickly enter mainstream use. Siperstein, Pociask and Collins (2010) reported that 92\% of 1,169 Americans between the ages of 8 and 18 had either used or heard someone else use the word 'retarded' in daily speak. Indeed, in the 2012 US presidential debates Barack Obama was described as a 'retard' by political pundit Ann Coulter (CNN, 2012). When it was suggested to her that using this word was potentially offensive, she defended her use of 'retard' and provided a generic response of "screw them" to everyone who had complained (Lengell, 2012). This pejorative definition of the word retardation is now colloquially synonymous with sheer stupidity, incapability, worthlessness and valueless. The unfortunate side-effect of this change is that it further reinforces a stereotype of an individual with an intellectual disability as being a lesser member of the community. The Special Olympics movement started the 
'Spread the Word to End the Word' as a means of trying to raise community awareness about the 'dehumanizing and hurtful effects of the word 'retard(ed)' and encourage people to pledge to stop using the R-word' (R-Word, 2012b, on-line).

The power of words cannot be underestimated. Zimbardo (2008) describes how the process of using words can 'dehumanise' people through language, and that this is the starting point for social exclusion and potentially a stepping stone towards more serious actions. People with intellectual disabilities have long faced both overt and subtle discrimination and social exclusion (Hall, 2005). For example, the eugenics movement initially argued that people with intellectual disabilities were 'moronic' or 'feebleminded' and therefore inferior and undeserving of life (Dune, 2012). This concept culminated in widespread sterilization practices around the world that continued throughout the twentieth Century (Block, 2000) and the mass murder in Nazi Germany of tens of thousands of people with disabilities (Mostert, 2002). While there has been significant social and political change regarding individuals rights in the past decades (e.g. United Nations General Assembly, 2006), there remains an undercurrent of discrimination and social exclusion for associated with people with intellectual disability across living environments, age and access to health support services (Ali et al., 2013; Nicholson \& Cooper 2013; Wark, Hussain, \& Edwards, 2014). While words like 'retarded' remain in common usage as a derogatory term, this underlying discrimination and associated implication of worthlessness will remain difficult to reduce.

\section{Gay}

The concept and meaning of the word 'gay' has changed significantly over the last five centuries. For instance, in 1637 the word 'gay' described a state of immortality (Online Etymology Dictionary, 2013). By the late seventeenth century the term referred to the state of being addicted to pleasures (Warner, 2012). This assumed that the individual was hedonistic, carefree and minimally concerned with moral constraints. While these connotations of gay seem to relay a sense of happiness and freedom, they came with social judgment. For example, the word gay was used for female sex workers (gay woman), a womaniser (gay man) or a brothel (gay house) (Online Etymology Dictionary, 2013).

By the early twentieth century 'gay' was less of a social faux-pas as men and women who decided to remain single were associated with the concept. An example 
of this changing usage can be seen in the title of the book and film The Gay Falcon (1941) which features a womanising detective named Gay. This use of the word continued well into the mid-twentieth century where middle-aged bachelors could be described as 'gay' which simply indicated that he was unattached and free. This usage also applied to women with free-wheeling lifestyles and numerous male friends. The British comic strip Jane, first published in the 1930s, presented the adventures of Jane Gay (a play on the name Lady Jane Gray), a socially and sexually free woman. Far from implying homosexuality, these examples are amongst many of their time in which being 'gay' referred to the envious state of being unattached and the sexual freedom that comes with being single (Urban Dictionary, 2013).

Following post-war social reform and Western societies moving back towards more conservative positions in the twentieth century the word 'gay' began to be associated more explicitly with sexual deviancy. As such, its use to exclusively mean 'homosexual' was not necessarily farfetched. Western countries during this time were predominantly patriarchal. Men were expected to be highly masculine breadwinners and predominantly filled all the politically and economically powerful positions (Hollows, 2002). As such, those men who did not meet their perceived duty of marriage and maintaining, dressing or even acting in accordance with societal expectations of a man were assumed to be homosexual (Connell, 1992).

By 1952 homosexuality was formally pathologised as a sociopathic personality disturbance (APA, 1952) and was deemed illegal on most continents. Subsequently, the word 'gay' not only meant someone who went against common societal expectations but also an individual (most often a man) who was mentally ill and criminally inclined. Coming into the twenty first century, and in-line with international Gay Pride movements, the term 'gay' no longer denotes mental illness or criminality. However, the word has retained it connection to homosexuals (particularly gay men) and its relation to social and sexual deviance (Warner, 2012). In this timeframe, the word has also attained additional meaning amongst youth and within popular culture.

In contemporary youth and popular culture the word, is often used in derisive spirit (Sherwin, 2006). In this case the word 'gay' is used pejoratively and disparagingly towards an individual (e.g. 'you're so gay') and/or an activity (e.g. 'that activity was really gay'). Considering this context the word 'gay' has come to mean 
'lame', 'rubbish', 'useless' or 'worthless'. This pejorative usage has its origins in the late 1970s. Beginning in the 1980s and especially in the late 1990s, the usage as a generic insult became common among young people (Winterman, 2008).

While it may seem that the use of the word 'gay' has been accepted within contemporary Western culture media representatives and music artists recognise the homophobic nature when used in this way:

If I was gay, I would think hip-hop hates me.

Have you read the YouTube comments lately?

'Man, that's gay' gets dropped on the daily -

We become so numb to what we're saying (Macklemore, 2012).

While some may defend the usage of the word 'gay' in popular media (Sherwin, 2006), it is more readily being recognised as a manifestation of homophobic abuse (Grew, 2007a). For instance, the Minister for Children in the United Kingdom, Kevin Brennan, stated in response to the 'casual' use of homophobic language by mainstream radio DJs:

too often seen as harmless banter instead of the offensive insult that it really represents. ... To ignore this problem is to collude in it. The blind eye to casual name-calling, looking the other way because it is the easy option, is simply intolerable (Grew, 2007b, online).

While the current use of the word 'gay' is being acknowledged as homophobic and derogatory its use remains pervasive and detrimental. As with the word 'retarded', the emerged usage of gay to imply worthlessness has created an impediment to the societal acceptance of individual difference.

\section{Suicide}

The construction of suicide threats and attempts has tended to be labelled attentionseeking or manipulative; not to be taken seriously (Canetto, 1997; Canetto \& Lester, 1998; Lester, 1996). Survival is perversely perceived as 'failure'; threats become throw-away words, something said by one person (usually constructed as female) to scare another into changing their behaviour or decision. In this way, words around suicide have been seen to be framed around selfish desire, almost a childishness 
that demonstrates a grabbing 'want' rather than a 'considered' need. The fear attached to such a threat speaks to the guilt and shame that remain bound to suicide; the stigma that still stains the death (Cvinar, 2005; Minois, 1999; Sudak, Maxim, \& Carpenter, 2008).

However, language around suicide has shifted in more recent popular culture. There is less a sense of the suicidal person being manipulative, rather that a suicidal act should be performed in atonement for not fulfilling the needs of the other. In 2007, Timbaland, one of America's top hip-hop artists and producers, released a song called 'Kill Yourself'. A portion of its lyrics are as follows:

Go on ahead

Kill yourself, kill yourself, kill yourself

Go on, kill yourself, kill yourself, kill yourself

If I was you, I wouldn't feel myself....

If you still wanna hang

We'll come to get ya

Put the rope around your neck and jump, my nigga! (Timbaland, 2007)

In a genre well-criticised for its use of language around women and violence, little has been said about this chorus seemingly goading someone to suicide. It must be noted that this song didn't appear on a little-known album but one that made significant sales around the world (Sanneh, 2007; Van Gelder, 2007). Indeed, it is not just hip-hop that has incorporated throw-away lines taunting someone to suicide. Katy Perry's album 'One of the Boys' sold five million copies (RC, 2010) and includes the following lyrics from the song 'Ur So Gay':

I hope you hang yourself with your H\&M scarf

While jacking off listening to Mozart (Perry, 2008).

While this song has been roundly criticised for its homophobic narrative, in line with Macklemore's plea in the previously mentioned song 'Same Love', its introductory lines wish for someone else's (auto-erotic) suicide.

Indeed, language around suicide has long been difficult. In 2012, Beaton, Forster and Maple wrote about the difficulties still attached to describing suicide both in the media and academic world. Specifically focusing on the verb 'commit', they 
deconstructed the phrase 'commit suicide' in terms of its historical and legal constructs, as well as its meaning when someone has experienced suicidal behaviours or bereavement. They concluded that:

Using the word 'commit' within the context of suicide is not only unnecessary, it is also harmful.... such talk is often stuck in concepts from the past that perpetuate stigma, constrain thinking and reduce help-seeking behaviour. Those bereaved by suicide and those who have been suicidal themselves have commented on the negative and unhelpful effects of stigmatizing language (Beaton et al., 2012, pg. 731).

The way people feel that their experiences are perceived and articulated by others can greatly impact on their recovery (Maple et al., 2010; Sommer-Rotenberg, 1998). This reflects Saussurian beliefs around language; the way others talk about suicide not only reflects the emotionally and ethically loaded meanings attached to the words around suicide but also the speaker's lived experiences of suicidality, which can then negatively impact on the lived experience of the bereaved.

However, this is not to say that jokes are not, and cannot, be made about suicide. In a recent article, Lester explored the humour around suicide and the potential offense connected to them. Interestingly, in an academic journal called Death Studies, Lester still felt he had to justify the inclusion of some jokes by saying:

The fact is that there are books, cartoons, and jokes about suicide, and it is a worthwhile task to examine them and analyze them. I faced a dilemma, therefore, as to whether to include examples in this article, because to do so may offend some readers. However, as is common in many work settings where the stress level is high, there is a lot of joking among the staff who work with people in crises, often around suicide and the suicidal clients. Therefore, I decided to include some examples of this type of humor (Lester, 2012, pg. $664)$.

While an esteemed academic struggled with language and inclusion that was potentially problematised, if taken out of its specific context, this same reflection has not seemingly occurred with Timbaland's or Perry's song lyrics. Lester starts from the point of suicide as a tragedy and finds that humour is one way for people for deal 
with such difficult issues as pain, loss and grief. On the other hand, the aforementioned song lyrics also posit suicide as a terrible event but one that you wish upon someone you want punished, whether this punishment is for a lack of respect (Timbaland) or a difficult relationship (Perry). The language around suicide is used as a weapon to hurt others.

Yet, the problem here lies with how this weapon is used by people in and out of popular culture. 'Go on, kill yourself' is not just a song lyric but a comment all too commonly made in response to different posts on YouTube and other internet forums. Recently, many young people have started making videos using flashcards to tell their stories of abuse, depression and self-harm. While many comments have been supportive, others have taunted. Some of these young video-makers have survived their difficult periods, and have made more inspirational videos (see Jonah Mowry); others have suicided (see Amanda Todd). The liminal space in which these vulnerable young people exist make the compassionate use of language all the more important.

Indeed, it is important to reflect upon the consequences of throw-away language connected to suicide, whether articulated as taunt or threat. Even when language is simply used to express an extremity of emotion - 'Going to that class makes me want to jump off a cliff', 'That dress is so amazing, l'll kill myself if they don't have it in my size' - there is a presumption attached that deserves to be unpacked. Within the stigma surrounding suicide, the idea still appears to linger that a person seeking death will do so in secret, they will not tell anyone their intention. Silence seems to only strengthen the perception that death must be the intention. On the other hand, the intentions of those who speak openly about their suicidality, who are perceived to threaten, are viewed, to paraphrase Shakespeare, to 'signify nothing' (Canetto, 1997; Lester, 1996). This manipulation is only heightened in such throwaway language. Suiciding over a dress may indeed appear to be nonsensical when said outside any context; however, when placed within experiences of trauma, psychache, or chronic mental illness, the words become altogether different. The importance is then: how to tell the difference between throwaway language and words of intention? Again, the language we use, the ways in which we talk about suicide, needs to be better understood in terms of compassion and awareness. 


\section{Conclusion}

The words we use are "the primary symbolic medium through which cultural knowledge is communicated and instantiated, negotiated and contested, reproduced and transformed" (Garrett \& Baquedano-Lopez, 2002, pg. 339). However, just as cultural knowledge is dynamic, so is the language through which it is conveyed. While the meanings of the words 'retard' and 'gay' have changed throughout history, as has the acceptability their usage, phrases around 'suicide' are both used to hurt others beyond their naming or descriptive uses (as nouns, adjectives or verbs), but also in a casual unthinking manner.

The examination within this paper has looked at how these different words can be used to hurt and where they can support; where language becomes either a shield or a sword. What must be remembered is that language is learned from childhood; how we use words is dependent upon how we learned language to begin with and with whom we learned it. Language is ever-changing, whether it is what words mean or the way in which they are used and by whom; it cannot simply be presumed that words can be used in the same way tomorrow as they were yesterday and even today. Words can move from benign meanings to hurtful ones, or be reclaimed from harmful use into empowered phrases. We must always seek to continually learn language, to understand the hurt they can inflict, and to recognise the impact upon social inclusion or exclusion. With such compassion, it can be argued that language would become more a shield than sword. If language usage reflects the speaker's lived experience and can so deeply impact upon the listener, then understanding how to better understand the dynamic nature of these constructs is vital.

\section{Acknowledgements}

The authors acknowledge the contribution made by the Collaborative Research Network on Mental Health and Well-Being in Rural and Regional Communities, supported by the Department of Industry, Innovation, Science, Research and Tertiary Education, Commonwealth Government of Australia. 


\section{References}

Abbeduto, L. (2009). Editorial. American Journal on Intellectual and Developmental Disability 114(1), 1-2.

Ali, A., Scior, K., Ratti, V., Strydom, A., King, M., \& Hassiotis, A. (2013). Discrimination and Other Barriers to Accessing Health Care: Perspectives of Patients with Mild and Moderate Intellectual Disability and Their Carers. PLOS One. doi:0.1371/journal.pone.0070855

APA (American Psychiatric Association). (1952). Diagnostic and statistical manual of mental disorders ( $1^{\text {st }}$ edition). American Psychiatric Association, Washington.

APA (American Psychiatric Association). (2000). Diagnostic and statistical manual of mental disorders (4th edition: text revision).American Psychiatric Association, Washington.

APA (American Psychiatric Association). (2013). Diagnostic and statistical manual of mental disorders (5th edition). American Psychiatric Association, Washington.

Beaton, S. J., Forster, P. M., \& Maple, M. (2012). The language of suicide. The Psychologist, 25(10), 731.

Bleich, E. (2011). The rise of hate speech and hate crime laws in liberal democracies. Journal of Ethnic and Migration Studies, 37(6), 917-934.

Block, P. (2000). Sexuality, fertility, and danger: Twentieth-century images of women with cognitive disabilities. Sexuality and Disability, 18(4), 239-255.

Butler, J. (1997). Excitable speech: A politics of the performative. Routledge, New York.

Canetto, S. S. (1997). Meanings of gender and suicidal behavior during adolescence. Suicide \& Life-Threatening Behavior, 17, 339-351.

Canetto, S. S., \& Lester, D. (1998). Gender, culture, and suicidal behavior. Transcultural Psychiatry, 35, 163-190.

CNN. (2012). Ann Coulter's backward use of the 'r-word'. Retrieved from http://edition.cnn.com/2012/10/23/living/ann-coulter-obama-tweet/index.html.

Connell, R. W. (1992). A very straight gay: Masculinity, homosexual experience, and the dynamics of gender. American Sociological Review, 57(6), 735-751.

Culler, J. (1976). Saussure. London: Fontana.

Cvinar, J. G. (2005). Do suicide survivors suffer social stigma: A review of the literature. Perspectives in Psychiatric Care, 41, 14-21.

de Saussure, F. (1910-1911). Saussure's third course of lectures on General Linguistics (1910-1911): From the notebooks of Emile Constantin. Oxford: Pregamon Press.

Delgado, R. \& Stefancic, J. (2004). Understanding words that wound. Boulder, CO, US: Westview Press.

Devitt, M. \& Sterelny, K. (1999). Language and reality: An introduction to the philosophy of language. Oxford: Blackwell.

Dune, T. (2012). Constructions of sexuality and disability: Implications for people with cerebral palsy. Saarbrücken: Lambert Academic Publishing.

Forchtner, B. (2012). Critical discourse analysis. The Encyclopedia of Applied Linguistics. doi: 10.1002/9781405198431.wbeal0272

Garrett, P. B., \& Baquedano-Lopez, P. (2002). Language socialization: Reproduction and continuity, transformation and change. Annual Review of Anthropology, 31, 339-361.

Gee, J. P. (2014). An introduction to discourse analysis: Theory and method (4 ${ }^{\text {th }}$ ed.). New York: Routledge. 
Grew, T. (2007a). BBC's attitude to homophobic language 'damages children'. Retrieved from http://www.pinknews.co.uk/2007/07/05/bbcs-attitude-tohomophobic-language-damages-children/

Grew, T. (2007b). Government committed to stamping out gay bullying. Retrieved from http://www.pinknews.co.uk/2007/07/05/government-committed-tostamping-out-gay-bullying/

Hall, E. (2005). The entangled geographies of social exclusion/inclusion for people with learning disabilities. Health \& Place, 11(2), 107-115.

Harris, R. (1987). A critical commentary on the Cours de Linguistique Generale. Duckworth, London.

Harris. R. (1990). Language, Saussure and Wittgenstein: How to play games with words. London: Routledge.

Hollows, J. (2002). The bachelor dinner: Masculinity, class and cooking in Playboy, 1953-1961. Continuum: Journal of Media \& Cultural Studies, 16(2), 143-155.

Hurford, J. R. (1989). Biological evolution of the Saussurean sign as a component of the language acquisition device. Lingua, 77, 187-222.

Keely, K., \& Fink, L. (2011). Dangerous words: Recognizing the power of language by researching derogatory terms. English Journal, 100(4), 55-60.

Leets, L. (2002). Experiencing hate speech: Perceptions and responses to antisemitism and antigay speech. Journal of Social Issues, 58(2), 341-361.

Lengell, S. (2012). Ann Coulter defends saying 'R-word'. Retrieved from http://www.washingtontimes.com/blog/inside-politics/2012/oct/26/ann-coulterdefends-saying-r-word/

Lester, D. (1996). Sexism in suicidology. Homeostasis, 37, 83-88.

Lester, D. (2012). Reflections on jokes and cartoons about suicide. Death Studies, 36, 664-674.

Lewis, V., \& Kellett, M. (2004). Disability. In: Fraser, S., Lewis, V., Ding, S., Kellett, M. \& Robinson, C. (Eds.). Doing research with children and young people (pp. 191-205). London: Sage Publications.

Macklemore. (2012). 'Same love', The heist. Retrieved from http://www.azlyrics.com/lyrics/macklemore/samelove.html

Maple, M., Edwards, H., Plummer, D., \& Minichiello, V. (2010). Silenced voices: Hearing the stories of parents bereaved through the suicide death of a young adult child. Health \& Social Care in the Community, 18(3), 241-248.

Minois, G. (1999). History of suicide: Voluntary death in Western culture. Baltimore: The John Hopkins University Press.

Mostert, M. (2002). Useless eaters: Disability as genocidal marker in Nazi Germany. The Journal of Special Education, 36, 157-170.

Nicholson, L., \& Cooper, S. A. (2013). Social exclusion and people with intellectual disabilities: a rural-urban comparison. Journal of Intellectual Disability Research, 57(4), 333-346.

Online Etymology Dictionary. (2013). Gay. Retrieved from http://www.etymonline.com/index.php?allowed in frame=0\&search=gay\&sear chmode $=$ none

Perry, K. (2008). 'Ur So Gay', One of the Boys. Retrieved from http://www.azlyrics.com/lyrics/katyperry/ursogay.html

RC. (2010). 'Weekly US music releases: Katy Perry, Usher, Eels, and Fantasia'. The Independent. $23^{\text {rd }}$ August. Retrieved from http://www.independent.co.uk/artsentertainment/music/weekly-us-music-releases-katy-perry-usher-eels-andfantasia-2059960.html 
R-Word. (2012a). R-word counter. Retrieved from http://www.rwordcounter.org/

R-Word. (2012b). Spread the word to stop the word. Retrieved from http://www.rword.org/Default.aspx

Sanneh, K., (2007). Can the star make himself a star? The New York Times. $1^{\text {st }}$ April. Retrieved from http://www.nytimes.com/2007/04/01/arts/music/01sann.html?pagewanted=all \& $r=0$

Shea, P. B. (1999). Defining madness. Sydney: Hawkins Press.

Sherwin, A. (2006). Gay means rubbish, says BBC. London: Times newspaper online. Retrieved from http://www.thetimes.co.uk/tto/arts/article2406394.ece

Siperstein, G., Pociask, S. \& Collins, M. (2010). Sticks, stones, and stigma: A study of students' use of the derogatory term "retard". Intellectual and Developmental Disabilities, 48(2), 126-134.

Sommer-Rotenberg, D. (1998). Suicide and language. Canadian Medical Association Journal, 159(3), 239-240.

Sudak, H., Maxim, K. \& Carpenter, M. (2008). Suicide and stigma: A review of the literature and personal reflections. Academic Psychiatry, 32, 136-142.

Timbaland. (2007). 'Kill Yourself', Timbaland presents shock value. Retrieved from http://www.azlyrics.com/lyrics/timbaland/killyourself.html

United Nations General Assembly. (2006). Convention on the rights of persons with disabilities.

Retrieved

from

http://www.un.org/disabilities/convention/conventionfull.shtml

Urban Dictionary. (2009). Going the full retard. Retrieved from http://www.urbandictionary.com/define.php?term=going+full+retard

Urban Dictionary. (2013). Gay. $\quad$ Retrieved from http://www.urbandictionary.com/define.php?term=Gay\&defid=2220325

US Congress. (2012). S. $2781\left(111^{\text {th }}\right)$ : Rosa's law. Retrieved November from http://www.govtrack.us/congress/bills/111/s2781

Van Gelder, L. (2007). Arts, briefly. The New York Times. Retrieved from http://www.nytimes.com/2007/04/12/arts/12arts.html?pagewanted=print

Wark, S., Hussain, R., \& Edwards, H. (2014). Impediments to community-based care for people ageing with intellectual disability in rural New South Wales. Health \& Social Care in the Community, 22(6), 623-633.

Warner, S. (2012). Acts of gaiety: LGBT performance and the politics of pleasure. Michigan: University of Michigan Press.

Winterman, D. (2008). How 'gay' became children's insult of choice. Retrieved from http://news.bbc.co.uk/2/hi/7289390.stm

World Health Organisation. (2012). Mental health definition: intellectual disability. Retrieved from http://www.euro.who.int/en/what-we-do/healthtopics/noncommunicable-diseases/mental-

health/news/news/2010/15/childrens-right-to-family-life/definition-intellectualdisability.

Zimbardo, P. (2008). The Lucifer effect. New York: Random House. 


\section{Biographical notes}

Kathy McKay (PhD) is a researcher and lecturer in the School of Health at the University of New England, Australia. Her research focuses on narratives of suicidality and self-harm from marginalised communities and within literary spaces.

Stuart Wark (PhD) is the second year academic coordinator with the School of Rural Medicine at the University of New England, with primary research interests in the fields of intellectual disability, ageing and gerontology, rurality, and mental health.

Virginia Mapedzahama has a $\mathrm{PhD}$ in Sociology from the University of South Australia. She held a Post Doctoral Research Fellowship at Collaborative Research Network for Mental Health in Rural and Regional Communities at the University of New England. Her research interest is understanding the social construction of all categories of difference, meanings attached to this difference, how it is signified, lived and its implications for those assigned difference. She explores this interest in the context of migration, diaspora, blackness, race, racism and ethnicity.

Tinashe Dune holds Bachelor of Arts (Honours) in Psychology from Carleton University, a Master of Public Health in Human Sexuality from the Institute for Advanced Study in Human Sexuality and a PhD in Behavioural and Social Science in Health from the University of Sydney. Dr Dune was a Post Doctoral Research Fellow within Collaborative Research Network for Mental Health in Rural and Regional Communities at the University of New England (UNE) and is currently a Lecturer in Interprofessional Health Science at the University of Western Sydney. Her teaching, research and community engagement focus is on marginalised populations and social determinants of health.

Saifur Rahman holds a master and PhD degree in Epidemiology and Population Health from Johns Hopkins USA and the Australian National University respectively. He recently completed a Post Doctoral Research Fellowship at Collaborative Research Network for Mental Health in Rural and Regional Communities, University of New England (UNE) with a primary interest in design and implementation health research that target Aboriginal and multicultural Australian minority groups. 
Catherine MacPhail holds a PhD from the University of the Witwatersrand, South Africa. She is a Lecturer in the School of Health at the University of New England, Australia and holds honorary positions at the Wits Reproductive Health and HIV Institute and in the School of Public Health, University of the Witwatersrand. Her primary research interest is adolescent sexual health and wellbeing. 